\title{
Discurso: 50 años Escuela de Periodismo Universidad de Chile
}

Por Faride Zerán

Hace pocas semanas vimos en vivo y en directo cómo un tanque enfilaba sus cañones hacia el Hotel Palestina, en la Bagdad invadida por las fuerzas anglo-americanas, disparando su carga mortífera en contra de 300 periodistas independientes de todo el mundo que habían transformado las habitaciones de ese edificio en una gran sala de redacción. El resultado de ese ataque ya es conocido: dos periodistas muertos y otros tres heridos.

En 20 días de invasión habían caído una decena de corresponsales, desde el camarógrafo de Telecinco de Madrid José Couso, uno de los muertos ese mediodía de sangre en el Hotel Palestina, hasta el jordano Tarek Ayub de la televisión árabe Al Jazeera, cuando la casa desde donde trasmitía esa cadena qatarí también fue atacada .

Horas antes y desde el techo del mismo Hotel Palestina, otro periodista acaparaba la atención de sus colegas. Peter Arnett, de 68 años, ciudadano estadounidense de origen neocelandés, ganador del Premio Pulitzer por su cobertura en la guerra de Vietnam, y consagrado como estrella de la CNN por su trabajo en la Guerra del Golfo, había sido despedido por la cadena NBC por decir a través de la televisión iraquí que la ofensiva angloamericana estaba empantanada en las arenas del desierto. "Suceda lo que suceda nunca voy a dejar de contar la verdad sobre esta guerra", declaraba a sus colegas un Arnett aún conmovido.

La verdad y la independencia se jugaban contra dos frentes: el de la censura del régimen dictatorial de Saddam Hussein, y el de la propaganda impuesto por las tropas anglonorteamericanas que viajaban acompañadas por cientos de periodistas cuyos despachos oficiales ostentaban el mismo déficit de credibilidad que los emanados de la televisión iraquí.

En pleno siglo 21, y pese a toda la parafernalia derivada de la revolución tecnológica y sus redes planetarias de diarios electrónicos y cadenas de televisión que trasmiten al instante cada hecho que acontece en la aldea global, el periodismo se sigue batiendo en tres conceptos claves: el derecho a la información de las mayorías ; el principio ético insoslayable de apego a la verdad, y su deber de independencia de cualquier poder.

En tiempos de guerra o de paz, estos tres principios constitutivos de nuestra profesión son intransables. Es decir, En Chile, o en Bagdad, ayer y hoy el periodismo es el mismo y cualquier otra cosa que intente parecérsele es sólo un remedo.

Un remedo que sin duda sirve ya sea para alimentar el patético show que reduce al periodista a la figura del payaso en pos del espectáculo y la entretención que vende.

O bien para ubicarlo como un mero estafeta o incondicional servidor del poder económico, político o religioso de aquellos grandes consorcios periodísticos que anteponen sus propios intereses, muchas veces ocultos, a los de la ciudadanía.

Hace 30 años en Estados Unidos, la dueña del Washington Post, Khaterine Graham, se enfrentó a las presiones derivadas de las investigaciones que llevaban a cabo dos jóvenes periodistas donde demostraban las operación de espionaje al Partido Demócrata, y que culminó con la dimisión de Nixon a la Presidencia de la República, en 1974, y que conocemos como el caso Watergate..

La dueña del Post había sido advertida por sus asesores que el enfrentamiento con el poder podía tener consecuencias terribles tanto en el avisaje como en las licencias de televisión que la poseía la empresa. Katherine Graham esgrimió un argumento que hizo época: su empresa era un órgano de opinión pública y su obligación era servir ante todo, a los ciudadanos. 
En esos años en Chile, y en plena dictadura militar, no teníamos señoras Graham que develaran secretos enfrentándose al poder. Había otros señores- y algunos de ellos aún estánque desde sus consorcios periodísticos se hicieron parte y ayudaron al poder en una conspiración que aún hoy averguenza al periodismo chileno, y que tiene que ver con el silencio o la complicidad en la violación de los derechos humanos .

El caso de los 119, es paradigmático. 119 hombres y mujeres chilenos detenidos desaparecidos, y ocultados por un ardid periodístico que no sólo no investigó , sino que se hizo parte de este crimen presentándolos ante la opinión pública nacional e internacional como asesinados en el exterior por sus propios compañeros en una vendetta producto de divergencias políticas.

Cuando el mundo aplaudía Watergate, en Chile nuestros medios de comunicación, según el Informe Rettig, publicaron y difundieron la información que el gobierno les solicitaba sin preocuparse de averiguar la verdad, afectando el buen nombre y la dignidad de numerosas personas. Y cito textualmente la conclusión: " la desinformación de la opinión pública en estas materias contribuyó sin duda a la mantención de las violaciones de los derechos humanos en el país.".

En este contexto, de ayer y de hoy, la Escuela de Periodismo de la Universidad de Chile celebra sus 50 años de fundación y el medio siglo de periodismo universitario en el país.

No se trata entonces de una conmemoración acotada a una casa de estudios y a una escuela de periodismo de las treinta y tantas que hoy existen en Chile.

Estamos hablando del inicio de la formación universitaria del periodismo, que el rector de la Universidad de Chile de la época, Juvenal Hernández , sintetizaba asi:

"..el periodismo es el agente cultural, económico y social. Por esta razón me propuse crear esta escuela de profesionales veraces, inteligentes y sin prejuicios de ninguna clase. Debía darse en ella una preparación responsable, científica, política, social y sicológica.."

A la polémica planteada en esos comienzos de los años cincuenta en torno a si el periodista nace o se hace, el primer director de la Escuela de Periodismo de la Universidad de Chile, el escritor Ernesto Montenegro , respondía:

"Una escuela de periodismo bien programada une la formación técnica con la intelectual. La inteligencia del periodista robustecida con un bagaje de conocimientos...la habilidad para juzgar con más certeza y para criticar con más justicia...También permite acceder a una formación ética..El alto periodismo debe ser una escuela de integridad moral, de respeto por la verdad, de urbanidad y tolerancia bien entendidas.."

Si bien el 28 de mayo de 1952, se autoriza por ley la creación de la Escuela de Periodismo de la Universidad de Chile, el 20 de abril de 1953, ella recibe a su primer contingente de alumnos, 25 hombres y 15 mujeres, quienes escuchan emocionados su primera clase de Introducción al Periodismo dictada por Ramón Cortéz Ponce.

Ese es el inicio de esta historias marcada por la audacia y voluntad de un grupo de intelectuales y recogida por la lucidez de una Universidad que entendió que los cambios cuando son profundos no se anuncian. Simplemente se hacen.

Entre medio, varios locales, entre ellos la mítica escuela de periodismo ubicada en la calle Los Aromos, levantada gracias a la generosidad de la venezolana Clara Rosa Otero, quién donó el dinero para construirla.

Pero ese edificio fue traspasado ilegalmente a otra institución en los años ochenta, cuando la Universidad de Chile sufrió otro de los embates de los poderes fácticos que ha tenido que 
resistir en sus 160 años de historia, y que en aquella oportunidad consistió en fragmentarla arrebatándole parte de su patrimonio.

De los más de diez años de funcionamiento en los edificios que albergaron el cuartel general de la Dina y de su cabeza, Manuel Contreras, nos hacemos parte . Los periodistas no borramos la memoria. Al contrario, trabajamos con ella. Esos tres edificios marcaron un tiempo de abandono pero a la vez de luchas y proyectos.

Con el apoyo de los ex alumnos, y con la complicidad de varias generaciones de periodistas que se formaron en nuestra casa de estudios, los académicos, estudiantes y funcionarios levantamos nuestra utopía : recuperar el prestigio académico y la dignidad de nuestro entorno .

No se trataba sólo de volver a tener un edificio digno sino además un nuevo espíritu...otra alma.

Y sobre los cimientos de nuestra memoria, de aquella que nos remite a Los Aromos, a nuestro Mario Planet, el director que por una década, desde 1962 hasta 1972, enriqueció, modernizó, actualizó la formación del periodista incorporándola al ámbito de las ciencias sociales y de la comunicación, construimos la quimera del nuevo siglo.

Hoy, ratificamos nuestra deuda de gratitud con el actual rector de la Universidad de Chile , profesor Luis Riveros, y con las autoridades de la Casa de Bello que nos apoyaron en nuestra demanda de un edificio digno, que ya lo tenemos, y que nos siguen apoyando en nuestro proyecto de hacer de la escuela de periodismo universitaria más antigua de Chile, el mayor y mejor centro de formación académica y profesional de los periodistas, comunicadores y profesionales de la imagen de Chile y América Latina. .

Para ello contamos con un proyecto de desarrollo estratégico que pronto debe ser sancionado por las instancias superiores de la universidad.

De ser aprobado, como ya lo fue por el Consejo de Facultad de Ciencias Sociales, en los próximos meses deberíamos transformarnos en un Instituto Interdisciplinario de la Comunicación e Imagen, dando inicio así a una nueva etapa en la que el periodismo y la comunicación dialoguen e interactúen con distintas disciplinas ampliando sus horizontes de docencia, investigación y extensión, fortaleciendo así el pregrado, con la Escuela de Periodismo, y el posgrado, con nuestro Magister en Comunicación Social y promoviendo el estudio de la comunicación, reforzando nuestro Programa de Libertad de Expresión, y creando un nuevo postítulo, el primero en Chile, esta vez de Cine documental...

Estimadas autoridades, académicos, estudiantes, amigas, amigos...

Este medio siglo de formación universitaria del periodismo en Chile se enmarca en un escenario particular en todos los planos.

En el mundo, con la primera guerra del siglo 21, cuyos efectos aún están por verse, pero que en el plano del periodismo marcó un antes y un después en la valoración de la información independiente por una opinión pública que asumió que ver no es comprender.

En este contexto nos enorgullece que los dos periodistas chilenos que se mantuvieron en Bagdad, Santiago Pavlovic y Rafael Cavada, sean egresados de la Escuela de Periodismo de la Universidad de Chile.

En el escenario nacional, el país está convulsionado por una dinámica en que los medios han decidido transparentarlo todo, desde la vida privada de los desconocidos que animan la farándula hasta los casos de corrupción del poder político, y los supuestos ilícitos o faltas administrativas que tienen en jaque a personeros públicos e instituciones de la República. 
Felicitamos este destape informativo y destacamos el valor de la democracia que permite un clima de fiscalización informativa que durante 17 años estuvo ausente en la gran prensa chilena. Prensa que aún no investiga el escandaloso traspaso de empresas públicas a manos de privados, a fines de los ochenta, ni las circunstancias que convirtieron a familiares de Augusto Pinochet en un poder económico, por ejemplo.

En ese marco, recuerdo un decálogo acerca de los principios básicos del periodismo que se mantiene vigentes aún hoy, y que resulta interesante contrastar con nuestra realidad cotidiana:

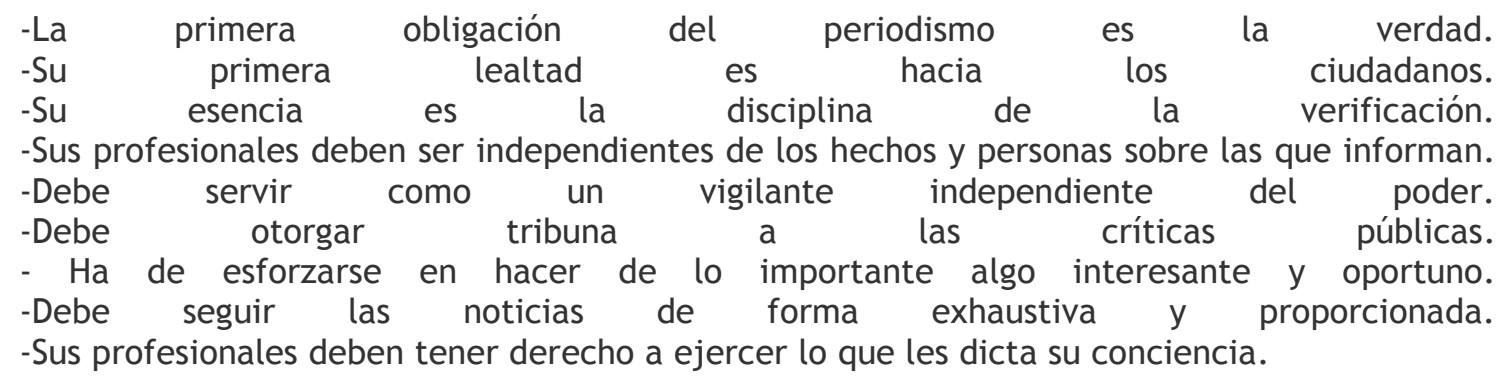

Nosotros, los periodistas no podemos eludir la noticia, cuyo eje está en la fiscalización de todos los poderes, sin excepción.

Por hacer efectiva esta premisa, que además se enmarca en la impronta democrática y su adhesión a la defensa de la libertad de expresión, muchos profesionales fueron encarcelados, torturados, asesinados o desaparecidos en los años de dictadura militar como Máximo Gedda, Augusto Carmona, Luis Durán, José Carrasco Tapia, Carlos Berger, o Diana Aaron, por citar a algunos en cuyos nombres rendimos homenaje a todos. .

Finalmente, y recuperando la esencia humanista de nuestra profesión, quiero leer el fragmento de una carta de Mario Planet, enviada desde su exilio argentino, en octubre de 1975, a su hija Pilar. Mario Planet había sido corresponsal del Time, y había cubierto la segunda guerra mundial. La carta dice:

"Querida pilarcita: ayer fue el día de mi madre y un nuevo aniversario del primer diario que fundé; elegí el 15 de octubre como un homenaje a ella y, entonces como hoy, estaba de regreso y planeando un nuevo viaje que luego se realizó, hasta que el día ocho de mayo del '45 saqué el segundo diario con un título que decía: "La guerra terminó a las 5", y creo que será el título de un libro que estoy dibujando.

Serán recuerdos de la guerra y de mis recorridos, pero sin que haya cañones ni torpedos. Alguien me preguntó una vez cuál era mi concepto -imagen de la guerra. Es muy simple. Es la visión de una chalupa con un malayo en los remos y dos niños rubios que miraban en silencio. La niñita tenía una muñeca en sus manos, como en tu retrato, y el niño iba vestido de marinero con pantalones cortos. Eran muy rubios y crespos.

Los zapatos eran de charol. El malayo los quería entregar al barco de evacuación en que yo viajaba, pero las reglas internacionales impidieron que los niños y sus pequeñas maletas fueran embarcados. El malayo con lágrimas en los ojos los acomodó con cariño y comenzó a remar.

Ese será el tema de mi libro. ¿Te parece?." (Buenos Aires, octubre 16, 1975).

Mario Planet murió en Santiago el 28 de junio de 1980. Con su recuerdo rendimos un homenaje a todos los académicos que en estos 50 años han aportado al desarrollo de la primera escuela de periodismo universitaria de Chile. 


\section{Muchas Gracias.}

* Pronunciado en abril de 2003 en el Salón de Honor de la Casa Central de la Universidad de Chile. 